\title{
Anastomotic Leakage after Upper Gastrointestinal Surgery: Endoscopic Treatment
}

\author{
Georg Kähler \\ Central Interdisciplinary Endoscopy, Medical Center Mannheim, University of Heidelberg, Mannheim, Germany
}

\section{Keywords}

Anastomotic leakage - Endoscopic management .

EndoVAC therapy · Self-expanding metal stents · Clipping

\section{Summary}

Anastomotic leakages substantially influence the outcome of patients after major surgery of the upper gastrointestinal tract. Endoscopy is important for making a diagnosis and for managing anastomotic leakages. By means of endoscopic inspection of the anastomotic site, not only the size and position of dehiscences but also the blood supply of the anastomotic region and an imminent leakage can be assessed. To close anastomotic leakages, several therapeutic methods are available, i.e. stenting, clipping, and the application of glue. In the majority of cases, the endoscopic application of a sponge for permanent suction (endoscopic vacuum-assisted closure therapy) is promising.

(C) 2017 S. Karger GmbH, Freiburg

\section{Introduction}

Anastomotic leakages are a specific complication after major surgery of the upper gastrointestinal tract. They are associated with increased mortality and prolonged stay in the intensive care unit. Due to its nature as an unintended severe adverse event, there are nearly no prospective trials about the management of anastomotic leakages. Thus, there is only limited evidence based on retrospective case series and expert experience.

\section{Endoscopic Assessment of Anastomosis}

Endoscopy plays an important role in making the diagnosis as well as regarding the treatment of anastomotic leakages after upper gastrointestinal surgery. Anastomotic leakages after resectional upper gastrointestinal surgery can occur nearly anytime during the first 3 weeks, mostly on day $3-5$, after operation. The shorter the time delay between operation and the occurrence of the anastomotic leakage, the more technical mistakes may arguably be the underlying cause. Blood supply of the anastomosis and nutritional aspects are more likely to be the pathophysiological background of this complication if the leakage occurs more than 5 days after primary surgery.

\section{Indication and Time Frame of Endoscopic Controls}

Clinical symptoms like fever, nausea, and exhaustion may be early symptoms of anastomotic leakages. With additional laboratory findings such as leukocytosis and increasing values of C-reactive protein or procalcitonin, the patient is suspected of suffering from an anastomotic leakage. Secretion of gas, food, feces, or bile from local drainages clearly indicates this diagnosis (table 1).

Endoscopy versus Radioscopy versus Computed Tomography Scan

Schaible et al. [1] published a study that compared endoscopic with radiological examination for anastomotic integrity in $35 \mathrm{pa}$ tients with transthoracic esophagectomy due to esophageal cancer. While radioscopy with a water-soluble contrast agent detected just one out of seven anastomotic leakages and had two false-positive results, endoscopy revealed every leakage and provided further findings such as ischemia in 6 patients.

Moreover, a prospective study from the field of radiology demonstrated the poor diagnostic value of contrast swallowing [2]. The authors recommend a computed tomography scan on day 7 as a prognostic marker for an uneventful course. They conclude: 'In case of doubt endoscopy is advisable'.

Because of its high sensitivity for anastomotic leakages and its therapeutic capabilities endoscopy should be the method of choice in all cases with a suspicion of leakage.

\section{KARGER}

() 2017 S. Karger GmbH, Freiburg

Fax +497614520714 
Tab. 1. Value of endoscopy for suspected anastomotic leakage

Advantages

Bedside application possible

Early diagnosis regarding secretion, local circulation at the anastomotic site, size and location of insufficiency

Option for therapy during the diagnostic procedure

\section{Disadvantages}

No information about space outside gastrointestinal tract

Mild patient discomfort

Experience-/examiner-dependent

\section{Characteristics of Endoscopic Findings}

The most important advantage of endoscopic inspection of the anastomotic site is the possibility to characterize the blood supply in the anastomotic region, the content of secretion, and the size and position of any leakage or pending defect. The latter can be recognized by supranormal fibrin secretion. This aspect is an indicator of a pending leakage (fig. 1-3).

\section{Endoscopic Therapy}

\section{Fibrin Glue}

Fibrin glue is a two-component system consisting of fibrinogen and highly concentrated thrombin. Mixing these two components induces a polymerization from fibrinogen into a fibrin network. Herein, fibroblastic cells grow and induce wound healing and scarring. The first report about the successful endoscopic management of anastomotic leakages with fibrin glue was published by Groitl and Scheele in 1987 [3]. This method was one of the first options for the endoscopic management of anastomotic leakages. Later case series reported moderate success rates especially in mild cases [4]. Of note, the fibrin glue applications have to be repeated many times. The best results can be achieved in the case of small leakages or residual small fistulas. It is important to note that the mechanism of action is not mechanical but biological. The fibrin glue should be injected into the tissue and not just into the lumen of the fistula. It is a medical blood product from human donors. Thus, the application of fibrin glue bears a risk of infection (hepatitis and HIV) and informed consent of the patient is required.

\section{Stenting}

Self-expanding metal mesh stents were established to treat malignant stenosis. Nowadays, they are also used for the treatment of benign diseases. Since metal mesh stents are available with a coating, they have the potential of tightening fistulas and leakages. Since there is typically no stenosis at the anastomotic site, stents with wide diameters from 23 to $35 \mathrm{~mm}$ are used.

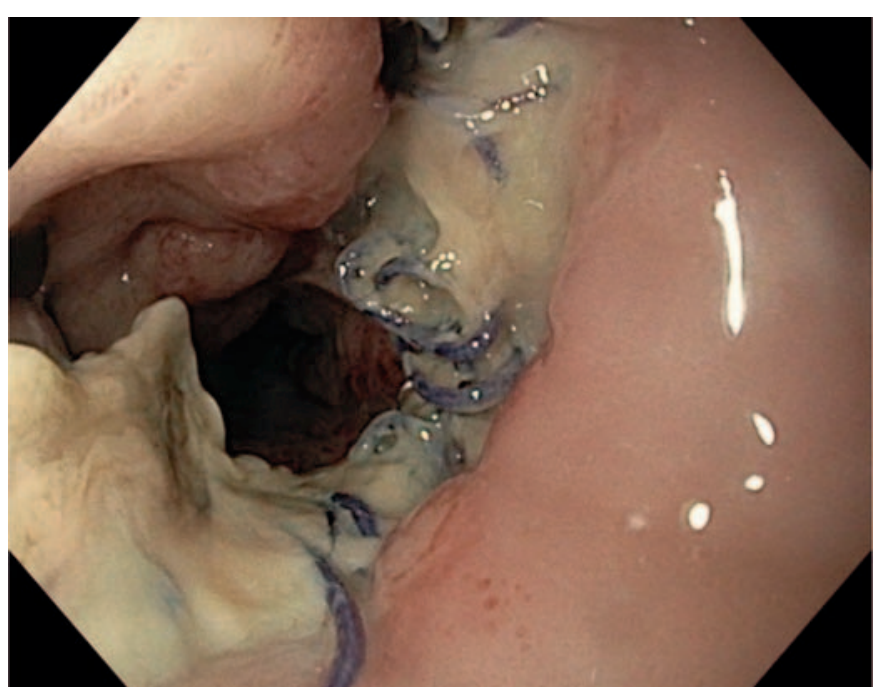

Fig. 1. No formal leakage but pending dehiscence after esophageal resection.

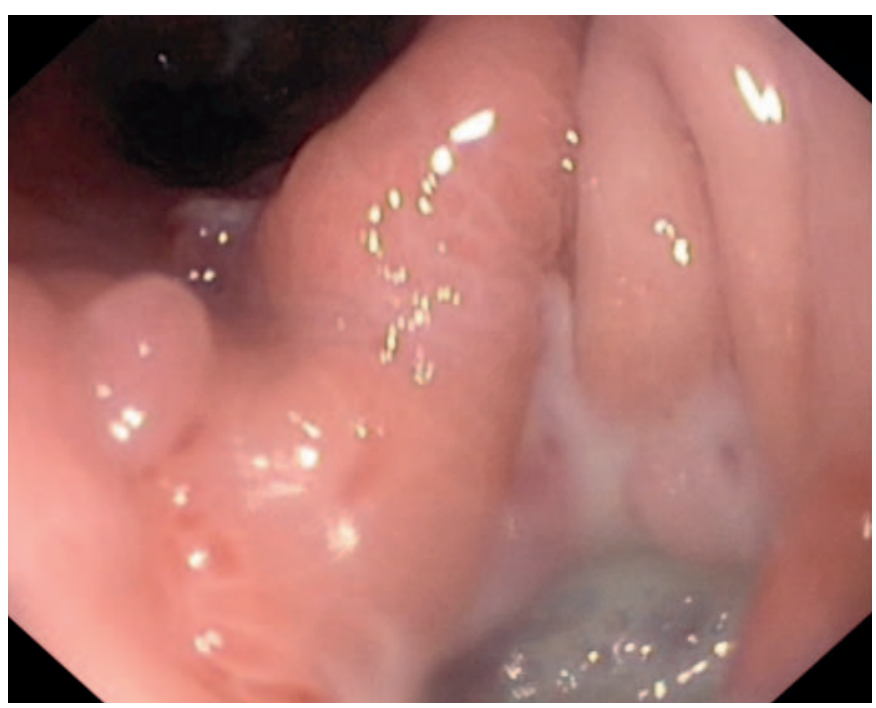

Fig. 2. Small leakage after gastric sleeve resection with intact surrounding.

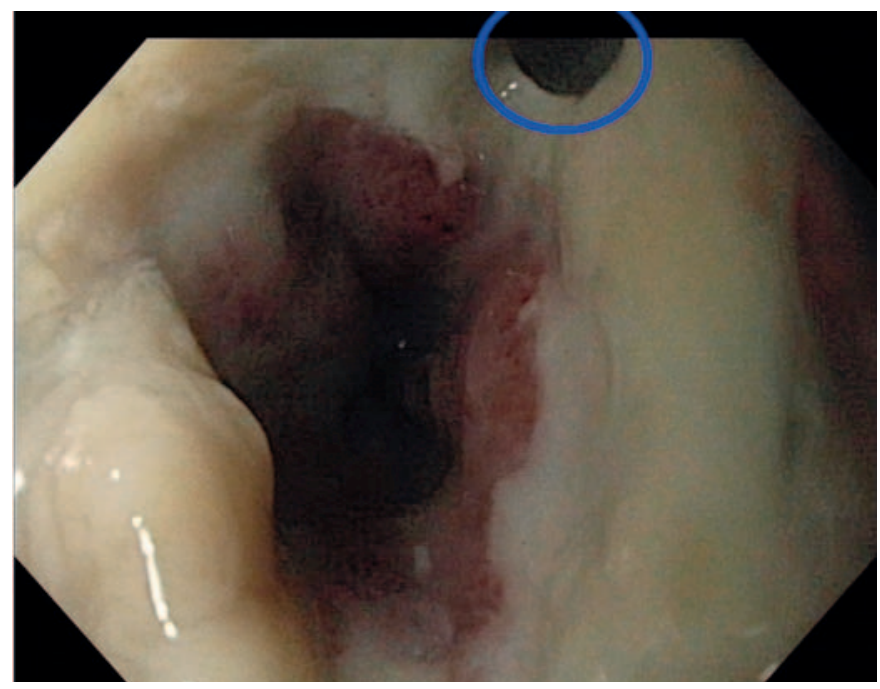

Fig. 3. Small leakage in an esophagogastric anastomosis with reduced blood supply and amounts of fibrin. 
Fig. 4. Contrast swallowing after stent placement in a 2-yearold child with anastomotic leakage after repair of an atresia of the esophagus.
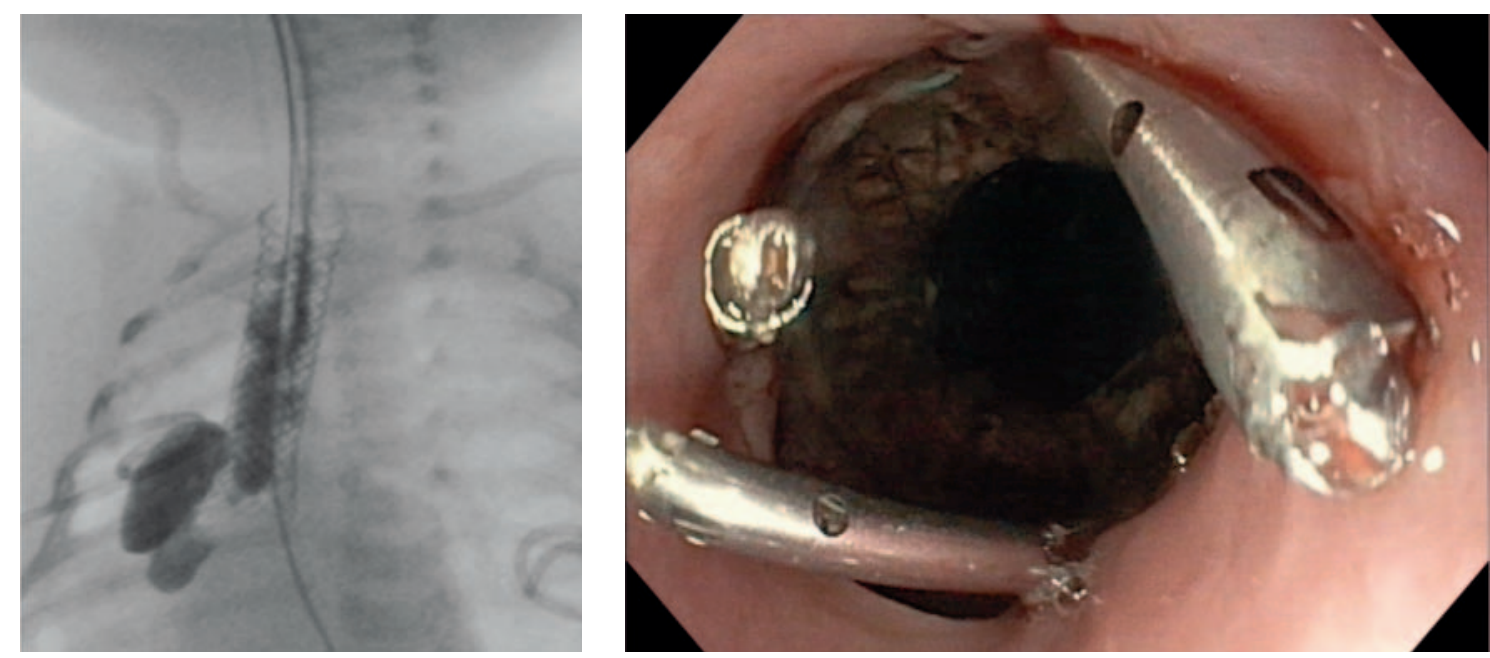

Fig. 5. Fixation of an esophageal stent with three clips (Resolution ${ }^{\mathrm{TM}}$ Clip; Boston Scientific Corporation, Marlborough, MA, USA)

technique might be helpful in cases with a good strength of the gastrointestinal wall edges. Few reports describe the use of throughthe-scope clips for closure [6]. In the past years, more reports about experiences with the over-the-scope clip (OTSC) have been published. This powerful clip has bigger arms and can grasp more tissue. Furthermore, additional instruments can grasp the wound edges and pull them into the clip. An international multicenter study from 2014 reported on 188 patients (108 fistulae, 48 perforations, and 32 leaks) with good success rates [7]. The long-term success was significantly higher when OTSCs were applied as the primary therapy (primary $69.1 \%$ vs. rescue $46.9 \%$; $p=0.004$ ). In multivariate analysis, patients who received OTSC placement for perforations and leaks had significantly higher long-term success rates compared with those who had fistulae (odds ratio 51.4 and 8.36, respectively) [7].

\section{Endoscopic Vacuum-Assisted Closure Therapy}

A very promising method to endoscopically manage anastomotic leakages is the endoscopic vacuum-assisted closure system (EndoVAC therapy).

\section{Basic Principles of EndoVAC Therapy}

The first report about vacuum therapy dates from Safronov in 1962 [8]. In the 1990s it became increasingly more applied in traumatology and for the treatment of infected wounds [9]. The permanent suction reduces wound secretion and edema, improves microcirculation, induces granulation of the wound, and decreases the wound size by retraction.

Special Aspects of EndoVAC Therapy in the Upper Gastrointestinal Tract

Because of the convincing results of vacuum therapy in the treatment of local infections, the adoption of this method for endomandatory when employing this type of endoscopic therapy. The 


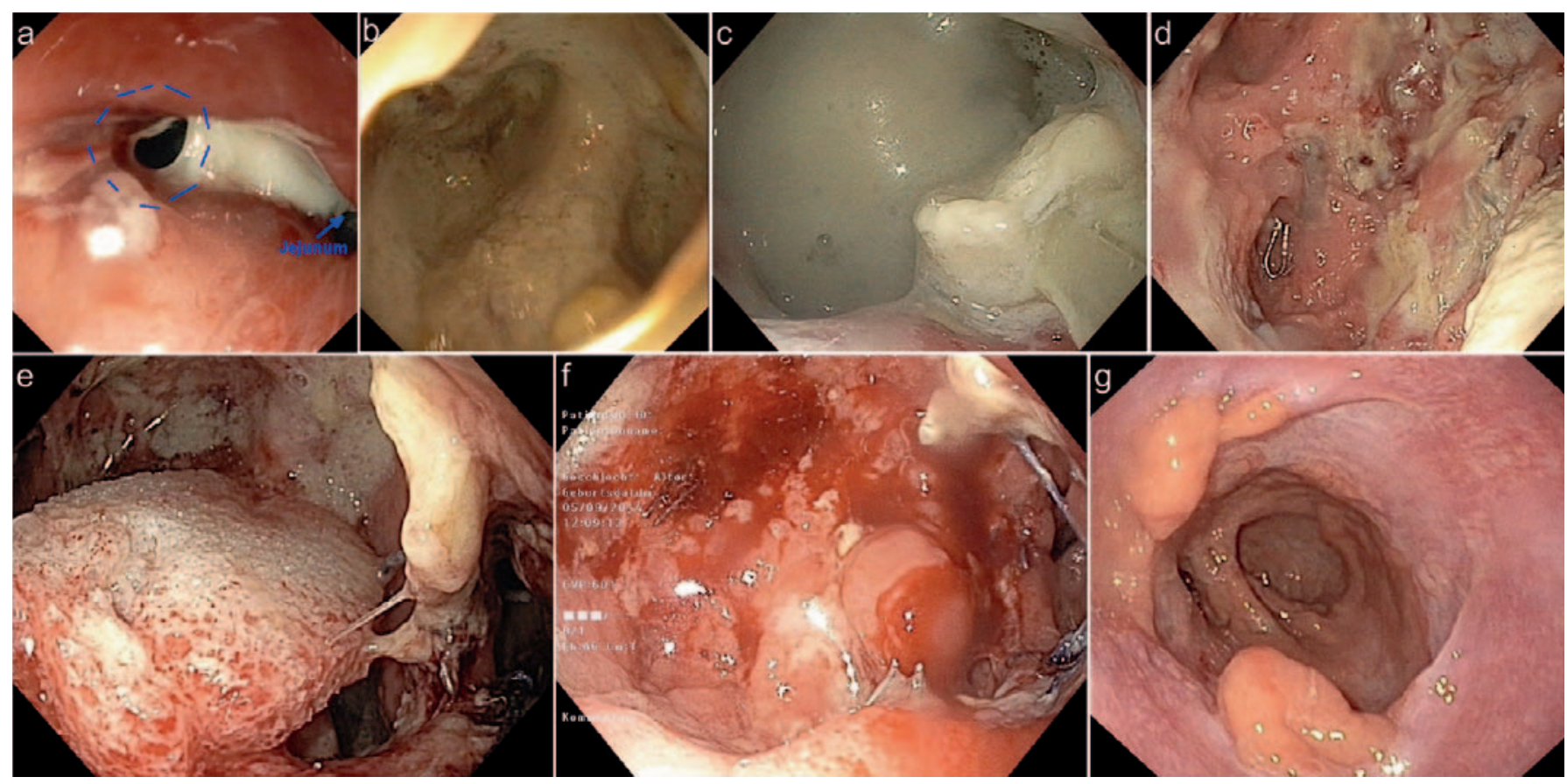

Fig. 6. 35-year-old patient with bariatric bypass after sleeve gastrectomy. a Postoperative day (POD) 3 - anastomotic insufficiency with fibrin; b POD 3 - view of the wound cavity; $\mathbf{c}$ POD 10 - enlargement of wound cavity; d POD 10 - after flushing of the abscess; $\mathbf{e}$ POD 10 - after placement of VAC sponge; $\mathbf{f}$ POD 14 cleaned wound with granulation tissue, end of VAC therapy; $\mathbf{g}$ control 5 months postoperatively.

scopic purposes was suggested. In 2008, Weidenhagen et al. [10] reported on EndoVAC treatment of anastomotic leakages after rectal resections. After the rapid spread of this new method, Loske and coworkers started to perform endoscopic vacuum therapy in patients with anastomotic leakages and sepsis in the upper gastrointestinal tract $[11,12]$.

The use of endo-sponges follows the same principles in the upper and lower gastrointestinal tract. Following endoscopic rinsing a sponge is placed in the cavity of the leakage. The sponge should be as small as possible but its diameter should guarantee that all parts of the wound are drained after the application of negative pressure. Furthermore, the sponge contains a drain which hauls out the exudate and ensures a permanent negative pressure. There is no evidence regarding the optimal pressure and the frequency of changing the sponge. Most authors recommend an exchange every 3 days and a negative pressure of $125 \mathrm{~mm} \mathrm{Hg}$.

Commercially available systems offer a prepared sponge with central drain that can be adapted to the individual shape of the lesion. Furthermore, the system contains an overtube, which facilitates the placement of the sponge. The sponge may also be placed into the intestinal lumen with therapeutic benefit, in particular if the leakage is too small to place the sponge through it (fig. 6).

The newest developments are tubes wrapped with fine porous films that apply the vacuum-assisted closure technique in narrow cavities $[13,14]$.

The experience with techniques such as rubber band ligation or with suturing systems is limited to case reports and cannot be recommended as a clinical standard technique for the treatment of anastomotic leakages.

\section{Nutrition Support}

In critically ill patients, the nutritional status contributes to a successful treatment of anastomotic leakages. Permanent enteral nutrition is beneficial for wound healing. Thus, the placement of a feeding tube is part of the endoscopic management of anastomotic insufficiency. If percutaneous endoscopic gastrostomy is not an option, the placement of a nasojejunal feeding tube is a valuable endoscopic treatment alternative. In cases of intended vacuum therapy, the feeding tube should be placed first. If the placement of a stent is intended, the feeding tube has to be placed subsequently.

\section{Conclusion}

The successful treatment of anastomotic leakages and other septic complications at the site of operation necessitates endoscopic support. Individual good expertise and skills with endoscopic interventions as well as familiarity with the management of postsurgical complications are necessary [13]. A good communication and cooperation of surgeons and endoscopists as well as interdisciplinary decision making are necessary to optimize the therapy for the individual patient with anastomotic leakages after upper gastrointestinal surgery.

\section{Disclosure Statement}

None. 


\section{References}

1 Schaible A, Sauer P, Hartwig W, et al: Radiologic versus endoscopic evaluation of the conduit after esophageal resection: a prospective, blinded, intraindividually controlled diagnostic study. Surg Endosc 2014;28 2078-2085

2 Strauss C, Mal F, Perniceni T, et al: Computed tomog raphy versus water-soluble contrast swallow in the detection of intrathoracic anastomotic leak complicating esophagogastrectomy (Ivor Lewis): a prospective study in 97 patients. Ann Surg 2010;251:647-651.

3 Groitl H, Scheele J: Initial experience with the endoscopic application of fibrin tissue adhesive in the upper gastrointestinal tract. Surg Endosc 1987;1:93-97.

4 Lippert E, Klebl FH, Schweller F, et al: Fibrin glue in the endoscopic treatment of fistulae and anastomotic leakages of the gastrointestinal tract. Int J Colorectal Dis 2011;26:303-311.

5 Feith M, Gillen S, Schuster T, Theisen J, Friess H, Gertler R: Healing occurs in most patients that receive endoscopic stents for anastomotic leakage; dislocation remains a problem. Clin Gastroenterol Hepatol 2011;9: 202-210
6 Rodella L, Laterza E, De Manzoni G, et al: Endoscopic clipping of anastomotic leakages in esophagogastric surgery. Endoscopy 1998;30:453-456.

7 Haito-Chavez Y, Law JK, Kratt T, et al: International multicenter experience with an over-the-scope clipping device for endoscopic management of GI defects (with video). Gastrointest Endosc 2014;80:610-622

8 Safronov AA: Vacuum therapy of trophic ulcers with simultaneous autoplastic skin transplantation (Article in Russian). Novyi Khirurgicheskii Arkhiv 1962;3:3-8.

9 Fleischmann W, Strecker W, Bombelli M, Kinzl L: Vacuum sealing as treatment of soft tissue damage in open fractures (Article in German). Unfallchirurg 1993;96:488-492.

10 Weidenhagen R, Gruetzner KU, Wiecken T, Spelsberg F, Jauch KW: Endoscopic vacuum-assisted closure of anastomotic leakage following anterior resection of the rectum: a new method. Surg Endosc 2008;22:18181825.

11 Loske G, Müller C: Endoscopic vacuum-assisted closure of upper intestinal anastomotic leaks. Gastrointest Endosc 2009;69:601-602; author reply 602.
12 Kuehn F, Loske G, Schiffmann L, Gock M, Klar E: Endoscopic vacuum therapy for various defects of the upper gastrointestinal tract. Surg Endosc 2017;DOI: 10.1007/s00464-016-5404-x.

13 Manta R, Caruso A, Cellini C, et al: Endoscopic management of patients with post-surgical leaks involving the gastrointestinal tract: a large case series. United European Gastroenterol J 2016;4:770-777.

14 Loske G, Schorsch T, Gobrecht O, Martens E, Rucktaschel F: Transgastric endoscopic vacuum therapy with a new open-pore film drainage device in a case of infective pancreatic necrosis. Endoscopy 2016; 48(suppl):E148-149. 